\title{
Effect of Non-linear Damper in Dynamic Vibration Absorber Behavior
}

\author{
Jasem M. Alrajhi , Ahmed Abed* \\ Automotive \& Marine Engineering Department Collage of Technological Studies/ Public Authority of Applied Education \& Training, \\ P.O.Box: 42325 Shuwaikh, 70654 - Kuwait \\ *Corresponding Author: A.abed@paaet.edu.kw
}

Copyright (C) 2014 Horizon Research Publishing All rights reserved.

\begin{abstract}
Dynamic vibration absorber (DVA) is used to reduce the system vibrations by converting the main system from one degree of freedom to two degrees of freedom. In this paper the effect of non-linear damper is tested, diesel engine with imbalance rotated mass is used to test the non-linear dynamic vibration absorber (NDVA), the diesel engine response of the DVA behavior for both linear and non-linear dampers is created using mathematical model and MATLAB software.
\end{abstract}

Keywords DVA, Response, Vibration, Dynamic

\section{Introduction}

Viscous damper consists of piston and cylinder, Lee and Taylor [1] showed the nonlinear formula of viscous damper, the obtained formula of the damper is nonlinear and the damping force depends on velocity and damper geometry.

Najafi, Ashory, and Jamshidi [2] they suggested different models for vibration absorbers, the suggested models are selected based on the arrangements of the absorber mass and springs, the results showed the optimum dynamic vibration absorber.

The study of nonlinear dampers is presented in Skup [3] paper, a one degree of freedom mechanical vibration system with non-linear dampers is tested to show the effect of nonlinear damping on the system response and frequency. The non-traditional dampers are presented in Kim, Won, and Ziegert [4] study, they found the main damping parameters for wind mill dampers also the theoretical results and the actual values are compared, the results showed that the experimental and mathematical model are closed.

[5] Nonlinear friction is presented, the damping or friction is produced from mass sliding over rough surface, the study showed the optimal values of friction or damping coefficient.

\section{Mathematical Model}

The nonlinear dynamic vibration absorber NDVA is tested on diesel engine with imbalance, the engine and NDVA are shown in (fig.1) below.

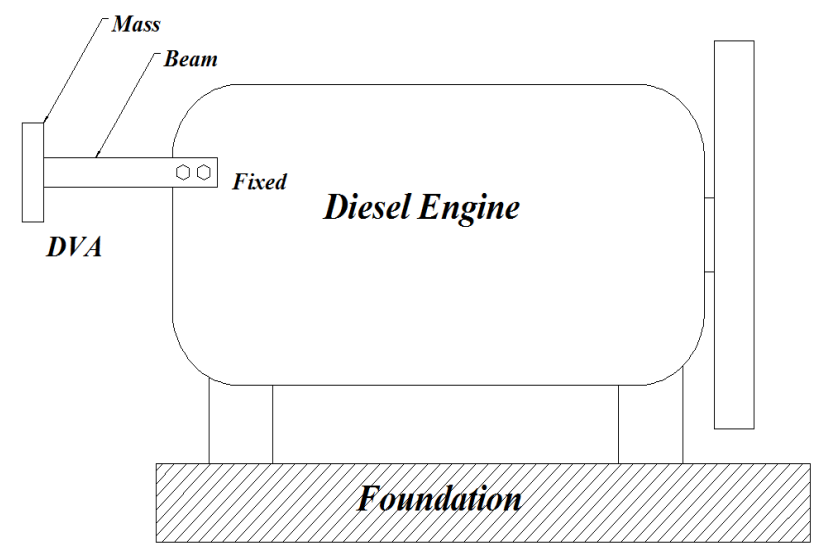

Figure 1. Diesel Engine with dynamic vibration absorber

The diesel engine is modeled as one degree of freedom system, $\mathrm{m}_{\mathrm{p}}$ is the engine mass, $\mathrm{K}_{\mathrm{p}}$ and $\mathrm{C}_{\mathrm{p}}$ are the foundation stiffness and damping coefficients. The DVA has mass $\mathrm{m}_{\mathrm{a}}$, stiffness $K_{a}$, and damping coefficient $C_{a}$. (fig. 2) shows the mechanical dynamic structure of engine with absorber.

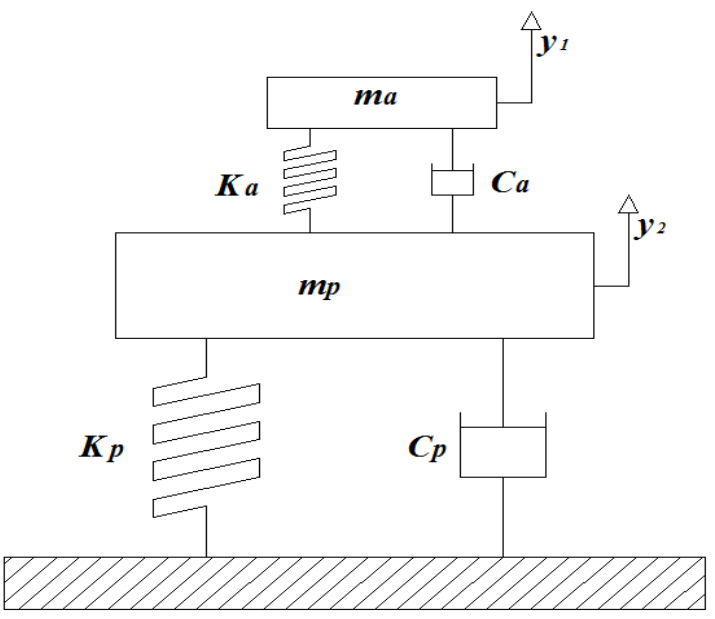

Figure 2. Dynamic model of engine with absorber. 
The system is two degrees of freedom system, the equations of motion are obtained using newton second law, the force analysis shows the forces on engine and absorber, (fig. 3) shows free body diagram of diesel engine and dynamic absorber.

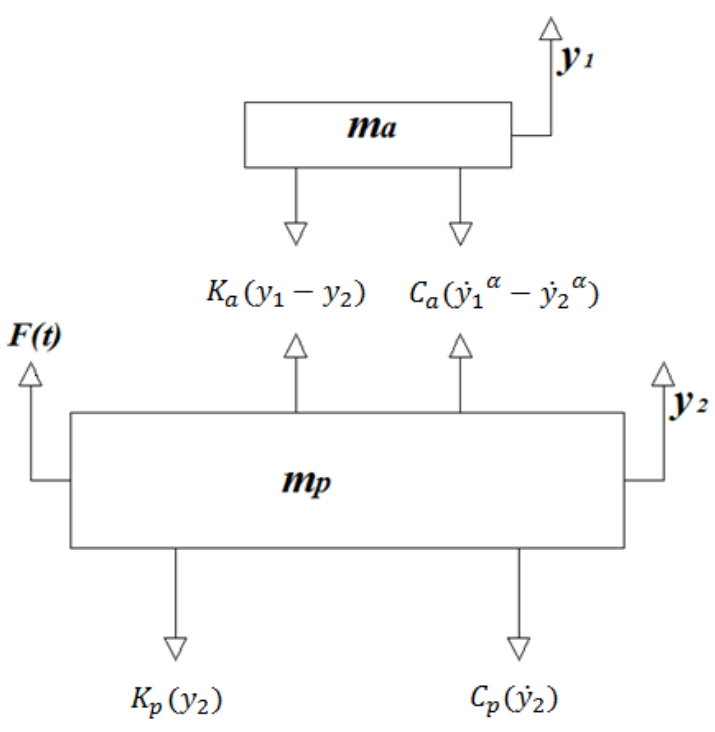

Figure 3. Diesel engine and NDVA free body diagram.

The imbalance force produced from engine is $F(t)$, the amount of the imbalance force depends on the engine rotational speed $\omega$, imbalance mass $m_{e}$, and the distance from imbalance mass to center of rotation $e$. by applying Newton second law two coupled nonlinear equations are produced:

$$
\begin{array}{r}
m_{a} \ddot{y}_{1}+C_{a} \dot{y}_{1}{ }^{\alpha}+K_{a} y_{1}-C_{a} \dot{y}_{2}{ }^{\alpha}-K_{a} y_{2}=0(1) \\
m_{p} \ddot{y}_{2}+C_{a} \dot{y}_{2}{ }^{\alpha}+C_{p} \dot{y}_{2}+\left(K_{a}+K_{p}\right) y_{2}-C_{a} \dot{y}_{1}{ }^{\alpha}-K_{a} y_{1}= \\
F(t)(2) \\
F(t)=F_{o} \sin (\omega t)(3)
\end{array}
$$

Equations (1) and (2) are written state space format so the second order ordinary differential equations are converted to four nonlinear first order ordinary differential equations, the variable $\boldsymbol{y}_{1}$ and $\boldsymbol{y}_{2}$ are replaced by $\boldsymbol{x}_{1}$ and $\boldsymbol{x}_{2}$ as shown below:

$$
\begin{gathered}
x_{1}=y_{1}, \dot{x}_{1}=x_{2}, \dot{x}_{2}=\ddot{y}_{1} \\
x_{3}=y_{2}, \dot{x}_{3}=x_{4}, \dot{x}_{4}=\ddot{y}_{2}(4) \\
\dot{x}_{1}=x_{2} \\
\dot{x}_{2}=\frac{K_{a}}{m_{a}} x_{3}+\frac{C_{a}}{m_{a}} x^{\alpha}-\frac{K_{a}}{m_{a}} x_{1}-\frac{C_{a}}{m_{a}} x_{2}{ }^{\alpha} \\
\dot{x}_{3}=x_{4} \\
\dot{x}_{4}=\frac{F(t)}{m_{p}}+\frac{K_{a}}{m_{p}} x_{1}+\frac{C_{a}}{m_{p}} x_{2}{ }^{\alpha}-\frac{\left(K_{p}+K_{a}\right)}{m_{p}} x_{3}-\frac{C_{p}}{m_{p}} x_{4}{ }^{\alpha}(5)
\end{gathered}
$$

The damping exponent for the nonlinear damper is located between 0.2 and 1.0 ; it depends on the damper design and damper physical parameters.

\section{Numerical Simulation and Results}

The set of non-linear differential equations are simulated using the predictor corrector time munching numerical solver ode $15 \mathrm{~s}$ of the MATLAB package. The physical parameters of diesel engine, foundation, and nonlinear dynamic vibration absorber are listed in table (1).

Table 1. Physical Parameters.

\begin{tabular}{|c|c|}
\hline Property & Value \\
\hline Diesel engine weight, $\mathrm{m}_{\mathrm{p}}$ & $250 \mathrm{~kg}$. \\
\hline Engine operation speed, $\omega$ & $96.0 \mathrm{rpm}$ \\
\hline Imbalance force amplitude, $\mathrm{F}_{\mathrm{o}}$ & $250 \mathrm{~N}$ \\
\hline Foundation Stiffness, $\mathrm{K}_{\mathrm{p}}$ & $1500000 \mathrm{~N} / \mathrm{m}$ \\
\hline Foundation damping coefficient, $\mathrm{C}_{\mathrm{p}}$ & $200 \mathrm{~N} . \mathrm{s} / \mathrm{m}$ \\
\hline Absorber mass, $\mathrm{m}_{\mathrm{a}}$ & $0.5 \mathrm{~kg}$ \\
\hline Absorber stiffness, $\mathrm{K}_{\mathrm{a}}$ & $1500 \mathrm{~N} / \mathrm{m}$ \\
\hline Absorber damping coefficient, $\mathrm{C}_{\mathrm{a}}$ & 0 \\
\hline
\end{tabular}

The results show the diesel engine amplitude with time for different damping coefficient exponent $\alpha$, the damping coefficient exponent values between 0.2 and 1. ( fig. 4) shows the engine amplitude for $\alpha=0.2$, amplitude of the diesel engine is decaying for all values of $\alpha<1$ due to nonlinearity effect, in ( fig. 6) the damping coefficient exponent $\alpha$ is 0.6 and after 200 seconds the engine vibration amplitude is zero. For $\alpha=1$ the vibration amplitude of the engine in increasing as shown in (fig. 7).

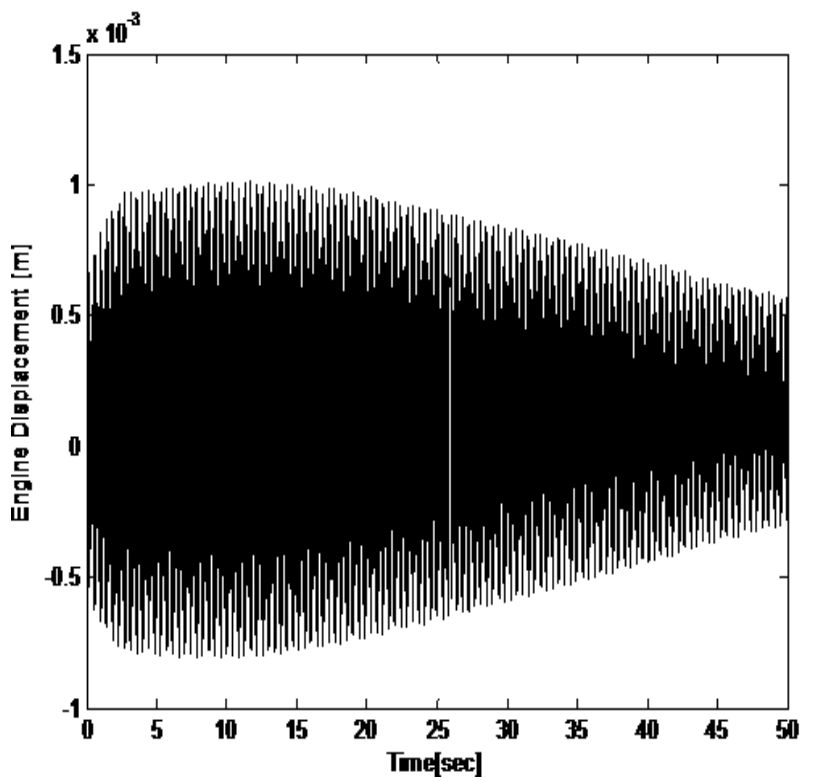

Figure 4. Diesel engine displacement [m] for damping exponent $\alpha=0.2$. 


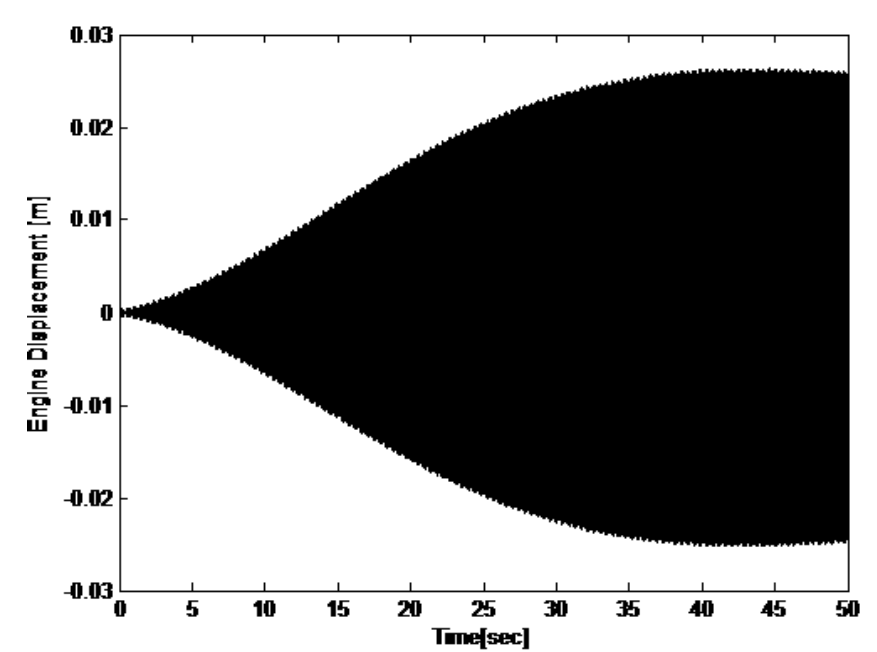

Figure 5. Diesel engine displacement [m] for damping exponent $\alpha=0.6$ during $50 \mathrm{sec}$ period.

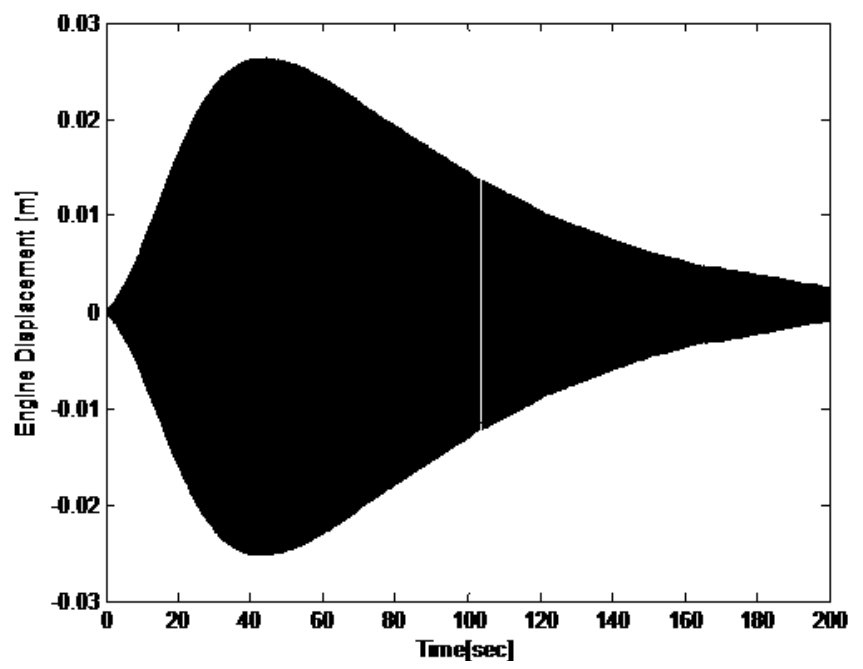

Figure 6. Diesel engine displacement [m] for damping exponent $\alpha=0.6$ during $200 \mathrm{sec}$ period.

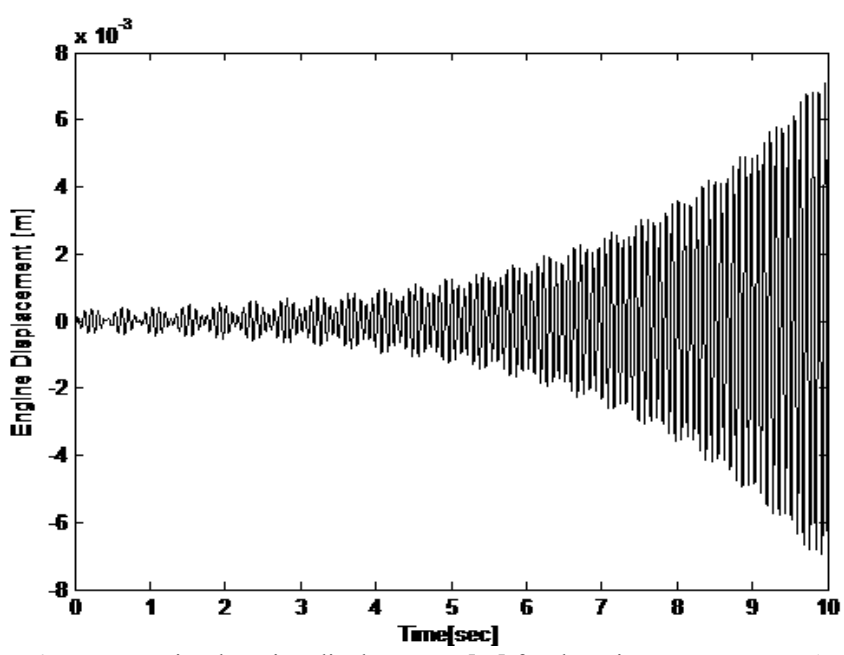

Figure 7. Diesel engine displacement [m] for damping exponent $\alpha=1$.

\section{Conclusions}

Dynamic vibration absorber is a passive energy absorber, absorber function is converting the system from one degree of freedom to two degrees of freedom so new frequencies below and above the main system operating frequency are appeared.

Viscous damper with damping coefficient exponent between 0.2 to 1 is used in the dynamic vibration absorber. Nonlinear vicious damper in the dynamic vibration absorber is tested in this paper on a diesel engine with imbalance mass; the results show that the nonlinearity effect reduces the vibration amplitude and the traditional DVA has no effect on the engine amplitude. It's recommended to study the effect of DVA with nonlinear combination of spring and damper unit.

\section{REFERENCES}

[1] D. Lee and D. P. Taylor, "Viscous Damper Development and Future Trends", John Wiley \& Sons, Ltd, 2001.

[2] M. Najafi, M.R. Ashory, and E. Jamshidi, "Optimum Configuration for Vibration Absorbers of a SDOF System Using Genethic Algorithm", Society for Experimental Mechanics Inc., 2009.

[3] ZbigniewSkup, "Analysis of Damping of Vibrations Through a Frictional Damper", Journal of Theoretical and Applied Mechanics, 2010, 48, 2, PP 465-478.

[4] Nam H. Kim, Dongki Won, and John C. Ziegert, "Numerical analysis and parameter study of a mechanical damper for use in long slender end mills", International Journal of Machine Tools \& Manufacture, 2006, 46, PP 500-507.

[5] E. EhsanMaaniMiandoab, A. Yousefi-Koma, and D.Ehyaei, "Optimal Design of an Impact Damper for a Nonlinear Friction-Driven Oscillator", International Journal of Mathematical Models and Methods in Applied Sciences, Issue 2, Volume 2, 2008, PP236-243. 